\title{
Design and Implementation of Space Vector Modulation Based Sliding Mode Control for Grid-Connected 3L-NPC Inverter
}

\author{
Fadia Sebaaly, Student, IEEE, Hani Vahedi, Student, IEEE, Hadi Y. Kanaan, Senior Member, \\ IEEE, Nazih Moubayed, Senior Member, IEEE, Kamal Al-Haddad, Fellow, IEEE
}

\begin{abstract}
This paper presents a closed-loop space vector modulation (SVM) based sliding mode controller (SMC) for a three-level grid connected neutral point clamped (3L-NPC) inverter. The nonlinear SMC based on Gao's reaching law has been designed to control the grid current and inject desired amount of active and reactive power into the network. Due to using single DC source at the NPC inverter DC bus, neutral point voltage is controlled through redundant switching states and instantaneous DC voltage feedback integrated into SVM technique. Meanwhile, there is no external voltage controller involved, thus no associated fine tuning issues are existed. The performance of the proposed hybrid controller to inject a desired active/reactive power to the grid is investigated through external perturbations such as change in the line current amplitude/phase shift, AC voltage fluctuation as well as DC voltage variation. Full converter state space model was developed and simulated. Experimental results are provided to verify the fast dynamic performance, low content of line current THD\%, and good voltage balancing of DC bus capacitors of the NPC inverter.
\end{abstract}

Index Terms-Space Vector Modulation, Sliding Mode Control, Multilevel Inverter, Grid Connected NPC, active rectifier, active filter.

\section{INTRODUCTION}

$\mathrm{T}$ HE huge growth in the accumulative total produced power from $1.2 \mathrm{GW}$ in 1992 to $136 \mathrm{GW}$ in 2013 has triggered the evolution of photovoltaic system [1]. In fact, the rapid cost reduction, $68 \%$ of the total cost, of the installed PV system was the main contributing factor to its widespread between 2000 and 2012 [2].

Manuscript received August 31, 2015; revised November 30, 2015, February 23, 2016 and March 28, 2016; accepted April 20, 2016. This work has been supported by the Agence Universitaire de la Francophonie (AUF), the Lebanese National Council for Scientific Research (CNRS-L), The Research Council of Saint Joseph University, the Canadian Research Chair in Electric Energy Conversion and Power Electronics (CRC-EECPE) and the Natural Sciences and Engineering Research Council of Canada (NSERC).

F. Sebaaly and H.Y. Kanaan are with the Saint Joseph University of Beirut, Faculty of Engineering-ESIB, Beirut 1107-2050, Lebanon (email: fadia_sebaaly@hotmail.com, hadi.kanaan@usj.edu.lb.

N. Moubayed is with the Lebanese University-Faculty of Engineering, Tripoli, 310, Lebanon (email:nmoubayed@ieee.org).

$\mathrm{H}$. Vahedi and K. Al-Haddad are with the Ecole de Technologie Superieure, University of Quebec, Montreal, Quebec, Canada H3C 1K3 (email: hani.vahedi@etsmtl.ca, kamal.al-haddad@etsmtl.ca.
The challenging task in developing power converters to meet the low cost and high efficient conversion scheme remains the big challenge for grid connected power conversion systems [3, 4]. For decade, major evolution from classical inverter topologies toward multilevel topologies has been introduced [5-7]. Neutral point clamped (NPC) topology is one of the most well-known type of multilevel converters and is widely spread in the market today for various industrial applications. NPC inverter has a common DC bus for three phases that makes it suitable for stand-alone and gridconnected applications where a renewable energy resource should be used and there are limits on the number of isolated DC supplies [8].

SMC has been proved to be one of the most effective nonlinear controllers featuring inherent compatibility with variable structure systems as power electronics converters due to switching actions. It could be combined with fixed switching frequency modulators (e.g. PWM or SVM) as a mandatory requirement for grid-connected converters to simplify design procedure of the output passive filters. Though model predictive control (MPC) is well known for its simplicity where neither PWM modulator nor voltage balancing regulator are required, however its variable switching frequency operation results in increasing switching losses and complicated procedure to design optimal filters. Most important SMC characteristics include robustness, system order reduction, insensitivity to plant parameters variations and external perturbations as well as simple implementation on digital processors which all have been proved in the literature [9-12]. Notice that, sliding mode control have been widely covered in literature but for grid connected inverters, attempts were focused on current control of a two-level inverters [13].

Neutral point voltage balancing is a mandatory control for NPC inverters normal operation. Various techniques have been reported in the literature including linear/nonlinear controllers $[14,15]$ as well as switching approaches that utilize redundant switching states in order to charge and discharge DC capacitors at required intervals [16-19]. SVM is one of the most popular online switching techniques that could instantly control the NPC DC capacitors voltages with a fixed switching frequency [20]. It also found industrial application due to using digital processors in the power converters currently [21].

In this paper, SMC and SVM have been combined to operate a grid-connected 3-level NPC inverter as a photovoltaic energy conversion unit. 


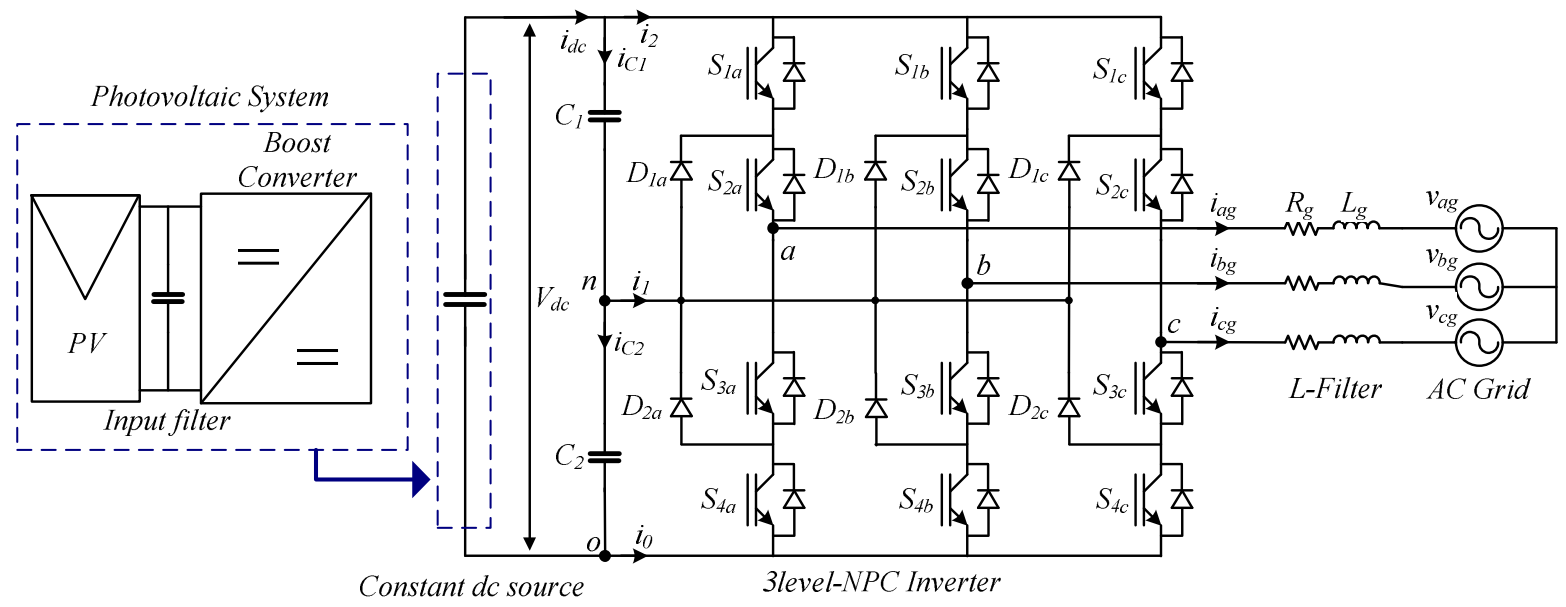

Fig. 1. Topology of grid-connected three-level neutral point clamped inverter

SMC is in charge of the grid current control to track the reference signal rapidly and reduce the harmonic components as much as possible while synchronizing the grid voltage and current instantaneously. Although SVM is used to assure the fixed switching frequency operation of the SMC, the major contribution of such hybrid controller is to decouple the current and voltage control loops which promise a fast and precise action in presence of any disturbances. To be clear, SVM plays an important role in balancing DC capacitors voltages that removes the need of an external controller which could make the overall system more complex with associated fine tuning issues. Since neutral point voltage is balanced by the SVM through redundant switching states, thus SMC can control the grid current without any additional input signals such as cases where a PI controller is used to balance DC capacitors voltages and its output is injected to the current control loop [22]. The hybrid technique is expected to show fast dynamic performances during any change in the system such as DC or AC voltage fluctuations as well as change in the reference value of the current injected into the grid.

NPC inverter modelling is done in section II. Section III and IV include the SMC and SVM design respectively. Experimental results are presented and discussed in section V which verifies the advantages of the proposed method in operating grid-connected power converters.

\section{Grid Connected Three-LeVel NPC InVERTER ModeL}

Fig. 1 shows the case study of a grid-connected 3L-NPC inverter. This topology has been introduced in 1981 [23] with split capacitors at DC side to reduce voltage stress on each device. The switching states are listed in Table I. The NPC inverter modeling and possible switching states have been studied in the previous [5]. In this work, the NPC is used to control the power flow generated by a photovoltaic system to the utility. The PV system, along with the boost converter is replaced by a constant dc voltage source. The connection of the inverter to the grid is done through an inductive L-filter. The main issue in the NPC topology is the accurate voltage balancing between upper and lower DC-link capacitors $\left(C_{l}\right.$ and $C_{2}$ ) which is expected to solve by the proposed switching technique as a major contribution in this work.
TABLE I

SWITCHING STATES AND CORRESPONDING OUTPUTS OF 3-LEVEL NPC

\begin{tabular}{cccccc}
\hline \hline Switching & \multicolumn{3}{c}{ Switching States } & \multicolumn{2}{c}{ Output Voltage } \\
States & $\mathrm{S}_{1 \mathrm{a}}$ & $\mathrm{S}_{2 \mathrm{a}}$ & $\mathrm{S}_{3 \mathrm{a}}$ & $\mathrm{S}_{4 \mathrm{a}}$ & $\mathrm{V}_{\mathrm{an}}$ \\
\hline 2 & 1 & 1 & 0 & 0 & $+\mathrm{V}_{\mathrm{dc}} / 2$ \\
1 & 0 & 1 & 1 & 0 & 0 \\
0 & 0 & 0 & 1 & 1 & $-\mathrm{V}_{\mathrm{dc}} / 2$ \\
\hline \hline
\end{tabular}

The grid side model of the system can be written as:

$L_{g} \frac{d i_{x g}}{d t}=v_{x g}-v_{x n}-R_{g} i_{x g}$

Where $L_{g}$ is the grid filter inductance and $R_{g}$ is the internal resistance of the inductor. $\mathrm{i}_{\mathrm{xg}}, v_{x g}, v_{x n}$ are grid currents, grid and inverter voltages respectively $(\mathrm{x}=\mathrm{a}, \mathrm{b}, \mathrm{c})$.

For more simplicity, the $a b c$ model is transformed to the synchronous reference frame (SRF). The natural frame $(a b c)$ grid line currents can be converted to synchronous reference frame $(d q)$ as

$\left[\begin{array}{l}i_{d g} \\ i_{q g}\end{array}\right]=\frac{2}{3}\left[\begin{array}{lll}\cos \left(\theta_{g}\right) & \cos \left(\theta_{g}-\frac{2 \pi}{3}\right) & \cos \left(\theta_{g}-\frac{4 \pi}{3}\right) \\ -\sin \left(\theta_{g}\right) & -\sin \left(\theta_{g}-\frac{2 \pi}{3}\right) & -\sin \left(\theta_{g}-\frac{4 \pi}{3}\right)\end{array}\right]\left[\begin{array}{l}i_{a g} \\ i_{b g} \\ i_{c g}\end{array}\right]$

The same transformation is used for the inverter output voltages and grid voltages. Where $\theta_{g}$ is the grid voltage angle that can be obtained by a phase-locked loop (PLL) [24]. Grid currents can be expressed in SRF in terms of grid voltages and inverter output voltages leading to the following $\mathrm{A}, \mathrm{B}$ and $\mathrm{C}$ matrixes; where $\omega_{g}$ is the angular frequency:

$\frac{d}{d t}\left[\begin{array}{l}i_{d g} \\ i_{q g}\end{array}\right]=A\left[\begin{array}{l}i_{d g} \\ i_{q g}\end{array}\right]+B\left[\begin{array}{l}u_{d} \\ u_{q}\end{array}\right]+C\left[\begin{array}{l}v_{d g} \\ v_{q g}\end{array}\right]$

$\mathrm{A}=\left[\begin{array}{cc}\frac{-R_{g}}{L_{g}} & \omega_{g} \\ -\omega_{g} & \frac{-R_{g}}{L_{g}}\end{array}\right] \quad \mathrm{B}=\left[\begin{array}{cc}\frac{V_{d c}}{L_{g}} & 0 \\ 0 & \frac{V_{d c}}{L_{g}}\end{array}\right] \quad \mathrm{C}=\left[\begin{array}{cc}\frac{-1}{L_{g}} & 0 \\ 0 & \frac{-1}{L_{g}}\end{array}\right]$ 


\section{SLiding Mode CuRRENT CONTROLLER Design}

As a current controller operating in SRF, two sliding surfaces were considered. $S_{d}$ for controlling the direct component of the grid current and $S_{q}$ for the indirect one:

$$
\left\{\begin{array}{l}
S_{d}=i_{d g}-i_{d g, r e f} \\
S_{q}=i_{q g}-i_{q g, r e f}
\end{array}\right.
$$

Where $i_{d g, \text { ref }}$ and $i_{q g, \text { ref }}$ are the direct and indirect current references that the system should track.

The grid active and reactive power are given in equation (5) assuming that the grid $\mathrm{q}$-axis represents the reactive component [21]. In order to ensure unity power factor operation, the system should inject only active power to the grid so as the reactive current reference $\left(i_{q g, r e f}\right)$ should be set to zero.

$$
\left\{\begin{array}{l}
P_{g}=+\frac{3}{2}\left(v_{d g} i_{d g}+v_{q g} i_{q g}\right)=+\frac{3}{2} v_{d g} i_{d g} \\
Q_{g}=-\frac{3}{2}\left(v_{q g} i_{d g}-v_{d g} i_{q g}\right)=-\frac{3}{2} v_{d g} i_{q g}
\end{array} \quad, v_{q g}=0\right.
$$

To achieve a sliding mode, currents components should track their references. Equivalent control law should be set in order to satisfy the condition as (6).

$$
\dot{\sigma}=0 \quad, \quad \sigma=\left[\begin{array}{l}
S_{d} \\
S_{q}
\end{array}\right]
$$

Where, $\sigma$ is the sliding surface vector and should be always null.

To resolve the problem of control law discontinuity, a reaching law based on Gao's method is therefore adopted. As explained in [25], this law assumes the operation in the three modes: reaching mode, sliding mode and steady-state mode, starting from any point and within a finite time. For reducing system chattering, authors have detailed a complete definition for quasi-sliding mode and proposed a reaching condition in form of (7) as:

$$
S(t)=-\varepsilon \operatorname{sgn}(S(t))-q S(t) \quad ; \varepsilon>0 \quad q>0
$$

In order to achieve a decoupled control for the system, assuming the equality, coupled currents are removed from the control law and derived as Eq. (8).

$\left\{\begin{array}{l}V_{d c} u_{d g}-v_{d g}=-\varepsilon_{d} \operatorname{sgn}\left(S_{d}\right)-q_{d} S_{d}-L_{d} w_{g} i_{q g} \\ V_{d c} u_{q g}-v_{q g}=-\varepsilon_{q} \operatorname{sgn}\left(S_{q}\right)-q_{q} S_{q}+L_{q} w_{g} i_{d g}\end{array}\right.$

Where $\left(\varepsilon_{d}, q_{d}\right)$ and $\left(\varepsilon_{q}, q_{q}\right)$ are d-axis and q-axis components for sliding current controller parameters respectively.

The derivative of (7) is given in (9):
$\left\{\begin{array}{l}\dot{S}_{d}=\dot{i}_{d g}-\dot{i}_{d g, r e f} \\ \dot{S}_{q}=\dot{i}_{q g}-\dot{i}_{q g, r e f}\end{array}\right.$

By substituting (9) into (3) and (4) and after simplifications, equation (10) is obtained. A schematic diagram is given in Fig. 2 introducing the details for the control of the current d-axis component. The same algorithm is adopted for the q-axis component.

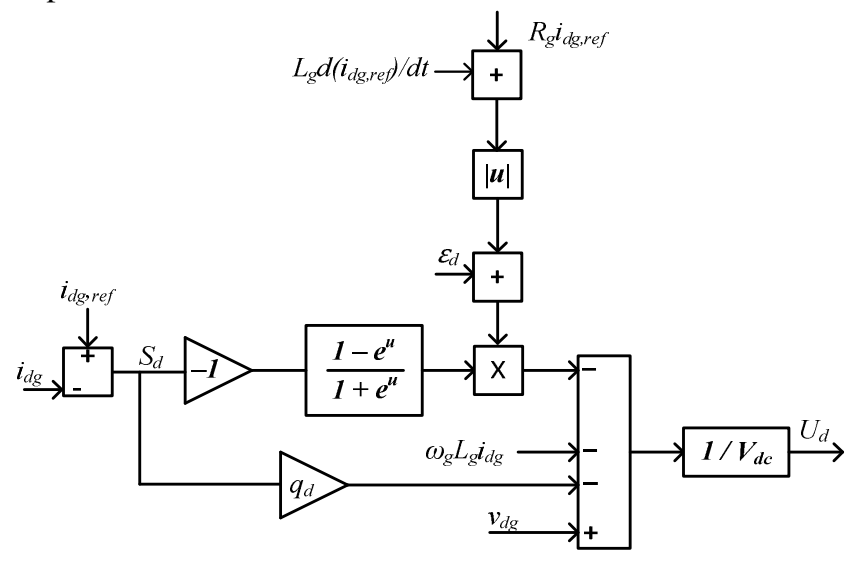

Fig. 2. d-Axis sliding mode control

$$
\left\{\begin{array}{l}
\dot{S}_{d}=-\frac{1}{L_{g}}\left[R_{g} S_{d}+\varepsilon_{d} \operatorname{sgn}\left(S_{d}\right)+q_{d} S_{d}+R_{g} i_{d g, r e f}+L_{g} \dot{i}_{d g, r e f}\right] \\
\dot{S}_{q}=-\frac{1}{L_{g}}\left[R_{g} S_{q}+\varepsilon_{q} \operatorname{sgn}\left(S_{q}\right)+q_{q} S_{q}+R_{g} i_{q g, r e f}+L_{g} \dot{i}_{q g, r e f}\right]
\end{array}\right.
$$

It is evident that the system stability is ensured by the following conditions:

$\left\{\begin{array}{l}S_{d} \dot{S}_{d}<0 \\ S_{q} \dot{S}_{q}<0\end{array}\right.$

Which yields in terms of $\varepsilon_{d}, \varepsilon_{q}, q_{d}$ and $q_{q}$.

$\left\{\begin{array}{l}q_{d}>0 \\ q_{q}>0 \\ \varepsilon_{d}=\left|R_{g} i_{d g, r e f}+L_{g} i_{d g, r e f}\right| \\ \varepsilon_{q}=\left|R_{g} i_{q g, r e f}+L_{g} i_{q g, r e f}\right|\end{array}\right.$

The same parameters conditions given by equation (11) are imposed in order to ensure a non-positive Lyapunov function given in (13).

$V=\frac{1}{2}\left(S_{d}^{2}+S_{q}^{2}\right)$ 


\section{PRoposed SVM INTEGRATED WITH VOLTAGE BALANCING TECHNIQUE}

The multilevel SVM has the same sectors but different regions than the conventional two-level one. As it is shown in Fig. 3, the space vector hexagon has six sectors and four regions per sector. The reference vector is placed in one of the four regions in each sector. Each triangle in this figure has three points which represents a voltage vector produced by associated switching states. Each voltage vector generated by switching states can be defined by [26]:

$\vec{V}_{x y z}=\frac{2}{3}\left(v_{a n}+a v_{b n}+a^{2} v_{c n}\right)$

\section{Where $a=e^{j(2 \pi / 3)}$.}

As it is clear in Fig. 3, seven voltage vectors can be produced by more than one switching states. These redundant switching states are the interesting characteristic of SVM which can be used in order to balance the capacitors voltage and to reduce switching frequency. The three-level SVM has $3^{3}=27$ switching states that include 8 redundant ones.

The concept of SVM is forming the reference vector $\left(V_{\text {ref }}\right)$ by three adjacent vectors which are produced by associated switching states and times. For instance, in Fig. 3, the illustrated $V_{\text {ref }}$ would be produced by applying three voltage vectors $V_{1}, V_{2}$ and $V_{3}$ that each one is generated by switching states 210,211 or 100,221 or 110 , respectively.

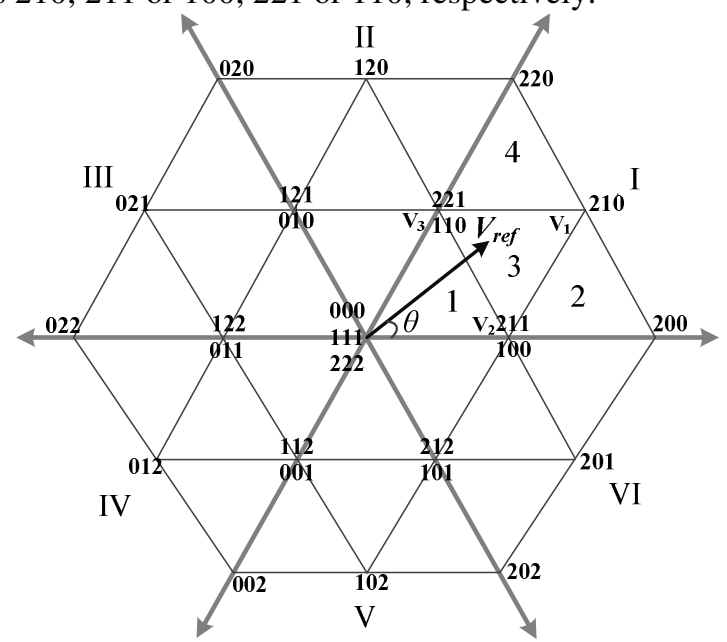

Fig. 3. 3-Level SVM hexagon including 6 sectors and 4 regions per sector

Voltage vectors would be applied to the switches proportional to the switching times $\left(t_{1}, t_{2}, t_{3}\right)$ which should be calculated precisely. Following relations clarify the concept of SVM.

$V_{1} t_{1}+V_{2} t_{2}+V_{3} t_{3}=V_{r e f} T_{s}$

$t_{1}+t_{2}+t_{3}=T_{s}$

Where, $T_{s}$ is the sampling period.

Five sectors (II to VI) can be mapped on first sector to simplify the calculations. Thus, all required calculations to obtain the three adjacent voltage vectors as well as associated time intervals are performed based on sector I and then it would be extended to the other sectors [20, 27]. Following five steps should be executed to produce the appropriate switching pulses in SVM technique:

1- The reference vector $\left(V_{r e f}\right)$ amplitude and phase is determined by converting the $a b c$ voltage vectors into $\alpha \beta$ coordination. The required matrix is defined as below:

$$
\left[\begin{array}{l}
v_{\alpha} \\
v_{\beta}
\end{array}\right]=\left[\begin{array}{ccc}
1 & \frac{-1}{2} & \frac{-1}{2} \\
0 & \frac{\sqrt{3}}{2} & \frac{-\sqrt{3}}{2}
\end{array}\right]\left[\begin{array}{l}
v_{a n} \\
v_{b n} \\
v_{c n}
\end{array}\right]
$$

Where, the $V_{\text {ref }}$ would be derived by (16).

$v_{\text {ref }}=v_{\alpha}+v_{\beta}=\left|V_{\text {ref }}\right| e^{j \theta}$

2- Based on the $a b c$ to $\alpha \beta$ transformation, the following equations can be used to calculate the amplitude and phase angle of the $V_{\text {ref }}$.

$$
\begin{aligned}
& \left|V_{\text {ref }}\right|=\sqrt{v_{\alpha}^{2}+v_{\beta}^{2}} \\
& \theta=\operatorname{Arctan}\left(\frac{v_{\beta}}{v_{\alpha}}\right)
\end{aligned}
$$

Using the reference vector angle, the location of the $V_{\text {ref }}$ is determined.

3- Analyzing the reference vector amplitude and angle leads to locating the region where it lays in. each region has its own three adjacent voltage vectors with associated switching states.

4- The time intervals for each voltage vector can be derived from following equations:

$$
\left\{\begin{array}{l}
t_{1}=T_{s}\left(2 m_{a} \sin \left(\theta+\frac{\pi}{3}\right)-1\right) \\
t_{2}=T_{s}\left(1-2 m_{a} \sin \theta\right) \\
t_{3}=T_{s}\left(1-2 m_{a} \sin \left(\frac{\pi}{3}-\theta\right)\right)
\end{array}\right.
$$

That is valid for $0 \leq \theta \leq \pi / 3 . m_{a}$ is the modulation index which is bounded between 0 and $1\left(0 \leq m_{a} \leq 1\right)$. It is defined as:

$m_{a}=\sqrt{3} \frac{\left|V_{r e f}\right|}{V_{d c}}$

5- Eventually, after obtaining the nearest three voltage vectors, based on the reference vector angle, the switching states of those vectors should be converted appropriately to the sector that the reference vector belongs to. Afterwards, the NPC switches are fired by the selected switching pulse durations using 7-segment timing as described clearly in [27]. 
As mentioned earlier, using SVM technique for 3-level NPC inverter facilitates balancing DC capacitors voltages due to having redundant switching states. According to redundancies shown in Fig. 3, switching sequences effects on upper DC capacitor voltage $\left(V_{C l}\right)$ is demonstrated which has been investigated in the literature [27]. Noticing at Table II, if $V_{\text {ref }}$ falls into regions 1 or 3 , then the switching algorithm can select between redundant states to balance the upper capacitor voltage. Since two capacitors are connected to the DC supply, regulating $V_{C l}$ at $V_{d d} 2$ means that $V_{C 2}$ is also balanced equal to the $V_{C l}$. The whole process of neutral point voltage balancing through SVM technique is depicted as a flowchart in Fig. 4.

TABLE II

EFFECT OF SWITCHING STATES IN REGIONS 1 AND 3 ON THE $V_{C 1}$

\begin{tabular}{ccc}
\hline \hline Region & Switching Sequence & $\mathrm{V}_{\mathrm{C} 1}$ \\
\hline 1 & $111-110-100-000-100-110-111$ & Decreasing \\
1 & $111-211-221-222-221-211-111$ & Increasing \\
3 & $100-110-210-211-210-110-100$ & Decreasing \\
3 & $221-211-210-110-210-211-221$ & Increasing \\
\hline \hline
\end{tabular}

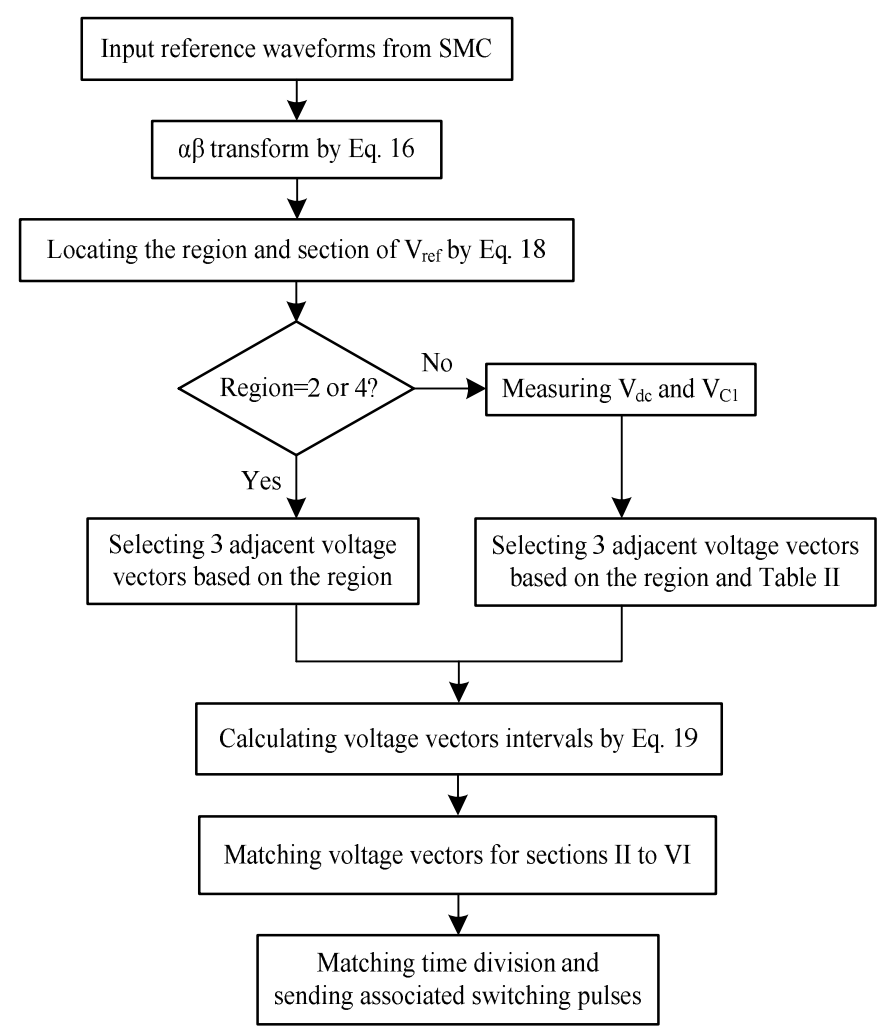

Fig. 4. Detailed logic of the applied voltage balancing technique and SVM

As illustrated by the flowchart, the SVM chooses the best switching sequence based on the input waveforms. All calculations are done based on sector I and at the end they are mapped to the real location of the $V_{\text {ref. }}$ as studied in details in the literature [20,27].
Since the reference vector passes all sectors and regions of the hexagon in each cycle, therefore it will fall into regions 1 or 3 that helps balancing the capacitors voltages. After finding voltage vectors, their switching times are calculated. Finally switching pulses are sent to the NPC inverter devices according to the computed intervals. As far as this algorithm produces the switching pulses based on real-time feedback signals from DC bus as well as the reference vector passes through all sectors of the hexagon, it is expected to have fast response and acceptable dynamic performance results in less voltage ripples of the DC capacitors even in unbalanced conditions.

As far as this algorithm produces the switching pulses based on real time feedback signals from DC bus, it is expected to have fast response and acceptable dynamic performance results with less voltage ripples of the DC capacitors even in power changing conditions. Moreover, one advantage of such online calculation is the ability of this algorithm for balancing the capacitors voltages in different situations including varying DC source amplitude.

The configuration of hybrid SMC-SVM control applied to the three-level (3L-NPC) grid connected inverter is shown in Fig. 5. The grid voltages and line current are obtained through their corresponding sensors. A PLL synchronization technique is adopted to extract the phase angle needed for the transformation to the (SRF) frame. The proposed current controller is applied to the system in (dq) frame. The current references $i_{d g, r e f}$ is given by the operator in order to inject the appropriate current amplitude to the grid and $i_{q g, r e f}$ is maintained at zero for unity power factor operation. The modulation stage is accomplished through an SVM modulator that takes in action firing the switches by maintaining the DC link voltages (upper and lower ones) equal. The overall control system takes in action to control the injected current and to stabilize the DC link voltages of the 3L-NPC without the need of PI regulator.

\section{EXPERIMENTAL RESULTS AND DISCUSSION}

The proposed control strategy was further validated experimentally using a laboratory system setup, as shown in Fig. 6. A Three-phase NPC inverter has been built and tested in grid-connected mode to validate the performance of the proposed SMC-SVM technique. Twelve $1.2 \mathrm{kV}, 35 \mathrm{~A} \mathrm{SiC}$ MOSFETs of type SCT2080KE and $6 \mathrm{SiC}$ fast-recovery clamping diodes of type SCS220KG are employed. The controller is implemented using the dSpace ds1103 real-time controller board with associated I/Os. The system parameters are given in Table III. 


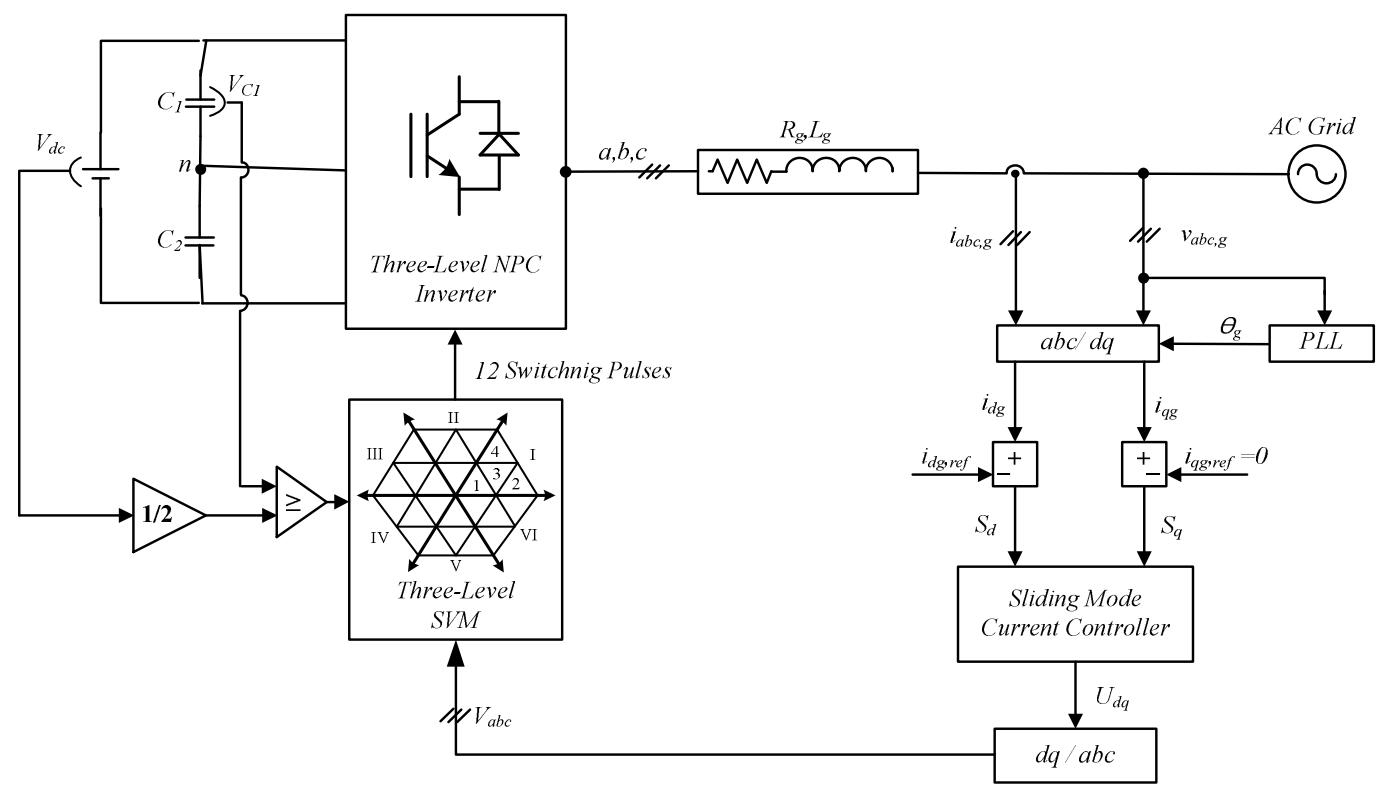

Fig. 5. Proposed SMC-SVM technique applied on a grid-connected three-level NPC inverter

TABLE III

EXPERIMENTAL SYSTEM PARAMETERS

\begin{tabular}{|c|l|c|}
\hline \hline Variable & Description & Values \\
\hline$V_{d c}$ & DC bus voltage $(\mathrm{V})$ & 330 \\
$f_{g}$ & Grid Frequency $(\mathrm{Hz})$ & 60 \\
$C_{l}, C_{2}$ & dc-link Capacitance $(\mu \mathrm{F})$ & 650 \\
$L_{g}$ & Line inductance $(\mathrm{mH})$ & 5 \\
$v_{x g}$ & Grid $r m s$ phase voltage $(\mathrm{V})$ & 100 \\
$i_{g}$ & Grid $r m s$ current $(\mathrm{A})$ & 3.5 \\
$f_{s w}$ & Switching frequency $(\mathrm{kHz})$ & 2 \\
\hline \multicolumn{2}{|c|}{ Sliding Current Controller Parameters } \\
\hline$\varepsilon_{d}$ & d-axis parameter 1 & 200 \\
$q_{d}$ & d-axis parameter 2 & 500 \\
$\varepsilon_{q}$ & q-axis parameter 1 & 400 \\
$q_{q}$ & q-axis parameter 2 & 200 \\
\hline \hline
\end{tabular}

Experimental results obtained in normal operation of the system show the performance of the proposed SMC-SVM algorithms. It should be mentioned that the system operates at low switching frequency of $2 \mathrm{kHz}$ which reduces the system switching losses and makes it suitable for high power grid integration system. The five levels of the 3L-NPC inverter are obtained in the phase-to-phase inverter output voltage as shown in Fig. 7. As well, the DC-capacitor voltage remains stabilized without the need of a regulator. The balancing of the DC capacitors voltages is accomplished with the SVM switching technique. Low voltage ripple of DC capacitor is measured at $2.4 \mathrm{~V}$ much less than $2 \%$ of 165.

As it was mentioned, according to the international standards IEC6000-1-2-3 and IEEE 555, the grid current harmonic content should not exceed $5 \%$ for a grid connected inverter. The THD of line current obtained is $1.8 \%$ with a power factor of $\mathrm{PF}=0.997$ as it is clear in Fig.8. In addition, the grid synchronization obtained at phases a and $\mathrm{b}$ depicted in Fig. 9 validates the proposed controller well. It should be noted that due to scope channel limitations only four signals can be illustrated each time.

In order to study the performance of the combined SMCSVM approach, several tests have been performed. Fig. 10 presents the operation of the system when tested by grid voltage variation of $10 \%$. The DC link capacitor voltages remains always controlled as well as the SMC controller takes into account the injection of a well-controlled current to the AC side.

To study the tracking behavior and the dynamic performance of the system, a $75 \%$ increase of the current reference amplitude has been applied to the system and the result is illustrated in Fig. 11. Capacitors voltages are still balanced and the current is controlled desirably as a consequent of appropriate performance of SMC-SVM technique. The balancing capability of the DC side voltages is tested when a perturbation is made by changing the DC voltage value from $330 \mathrm{~V}$ to $290 \mathrm{~V}$. The results are given in Fig. 12. It is clear that without a regulator the SVM algorithm operates normally and balances the DC link voltages under external perturbations. Moreover, the system continues to inject a synchronized current to the grid due to the robustness of the SMC controller. To extend the analysis for the voltage balancing limitations capability, the controller was tested for various output power. The controller was able to stabilize the DC link capacitors for a total power of $1.66 \mathrm{~kW}$ with voltage ripples of $4 \mathrm{~V}$ ( $2 \%$ of half the DC link bus voltage) acceptably.

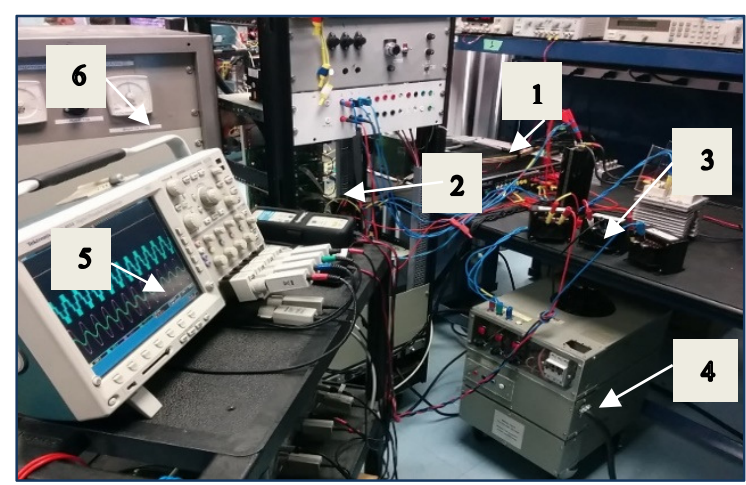

Fig. 6. Experimental test setup. (1) DS1103. (2) NPC inverter. (3) L-filter. (4) DC power supply (AC source \& rectifier).

(5) Oscilloscope. (6). Grid 


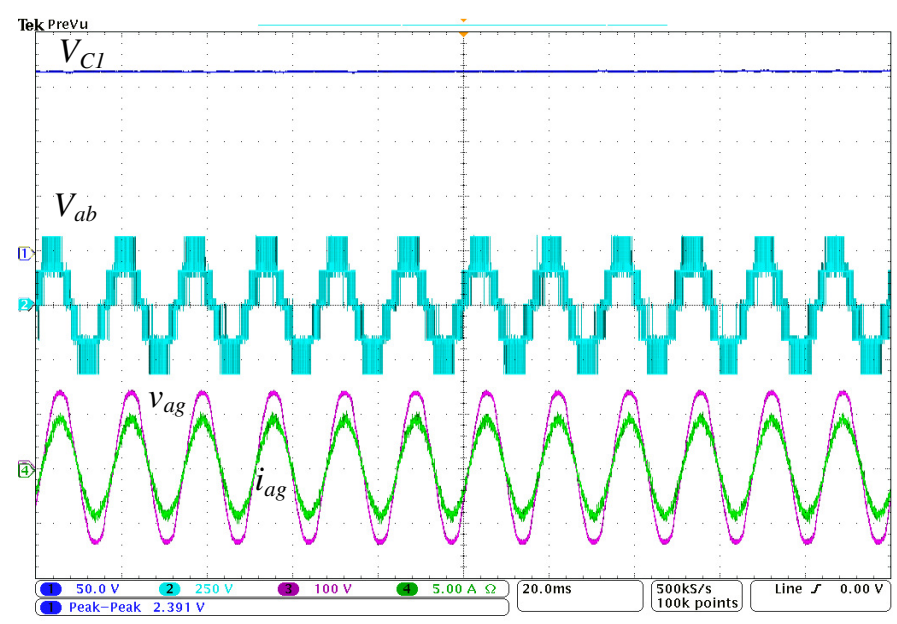

Fig. 7. Steady state voltages and currents waveforms of the grid connected inverter.

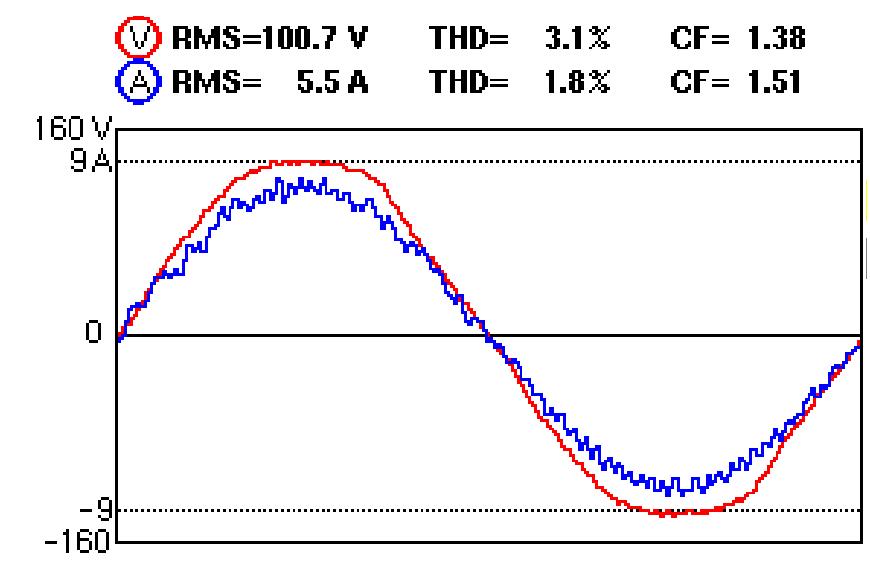

Fig. 8. Grid side voltage and current waveforms with THD and RMS values

Since converters have been recently asked to provide reactive power as an additional service, an experimental test is performed in which the inverter is exchanging reactive power with the grid while injecting some active power. The experimental results are illustrated in Fig. 13 where a change of $30^{\circ}$ in phase shift between the voltage and grid current has been applied to the controller. As it is clarified in the zoomed figures, the system continues to operate normally and always balancing the DC link voltages during this change. Capacitors voltages are depicted with low scale to clear the low voltage ripples accordingly.

For a clearer idea about the proposed controller system, the operation of the system has been tested for different switching frequencies while other parameters were kept unchanged. Fig. 14 shows the result when the system operates under different switching frequencies reaching the $12 \mathrm{kHz}$. The injected current THD remains always under the limits imposed by the international standards. It should be mentioned that the controller presents always good operation in stabilizing the DC link capacitor voltages.

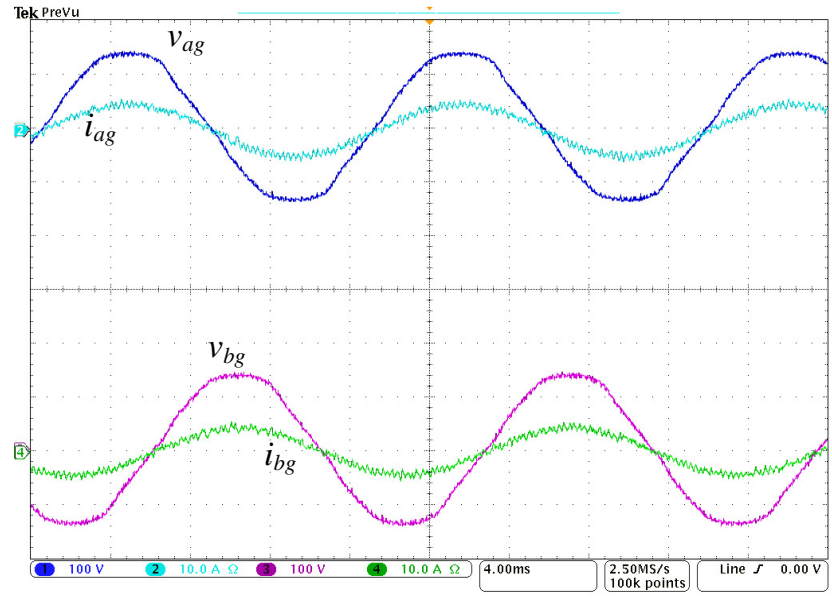

Fig. 9. Unity power factor operation: grid side voltages and currents

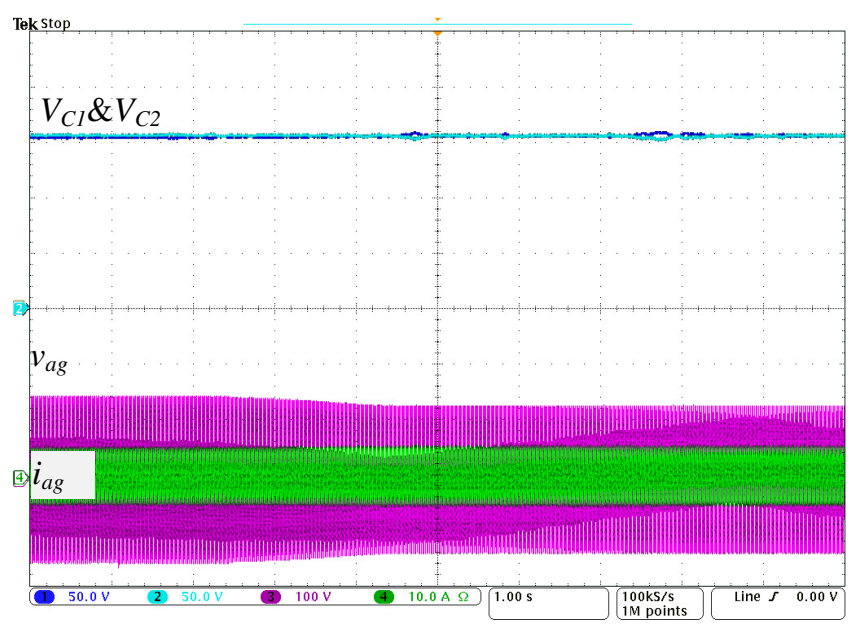

Fig. 10. Experimental results during grid voltage sag of $10 \%$

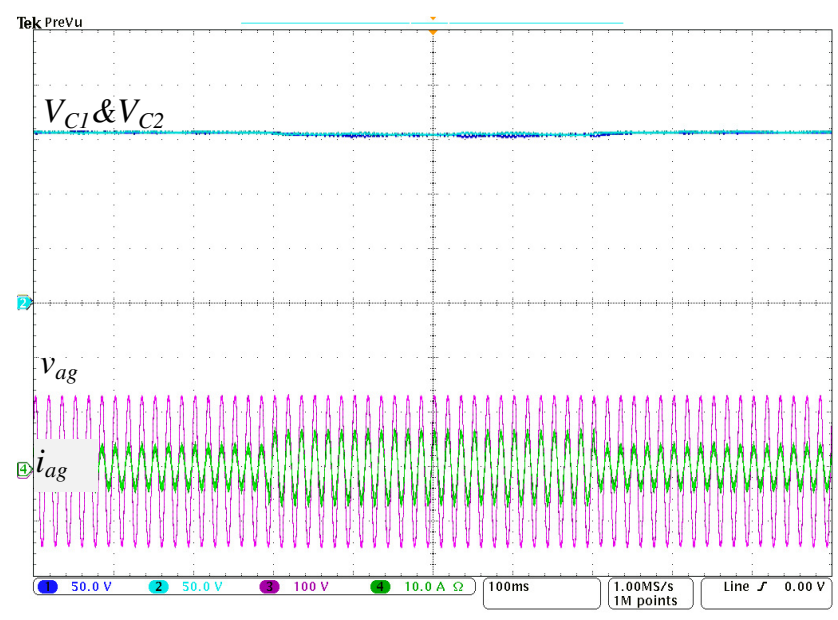

Fig. 11. Experimental results for a $75 \%$ step increase/decrease of current reference

Moreover, the system performance has been tested when the transmitted power to the AC side varies step-by-step. The results are depicted in Fig. 15 where the $\mathrm{THD}_{\mathrm{i}}$ and the power factor are depicted versus output power increases. As the total power injected increases (until 1.6kW), a lower THDi and higher power factor are almost achieved. A good current waveform is obtained when the rms current value is about 
2.1A.This result is normal for a sliding mode current controller, since for low current value the reaching condition will be hardly attained and the chattering effect will be significant. However it can be noted that the $\mathrm{THD}_{\mathrm{i}}$ obtained is

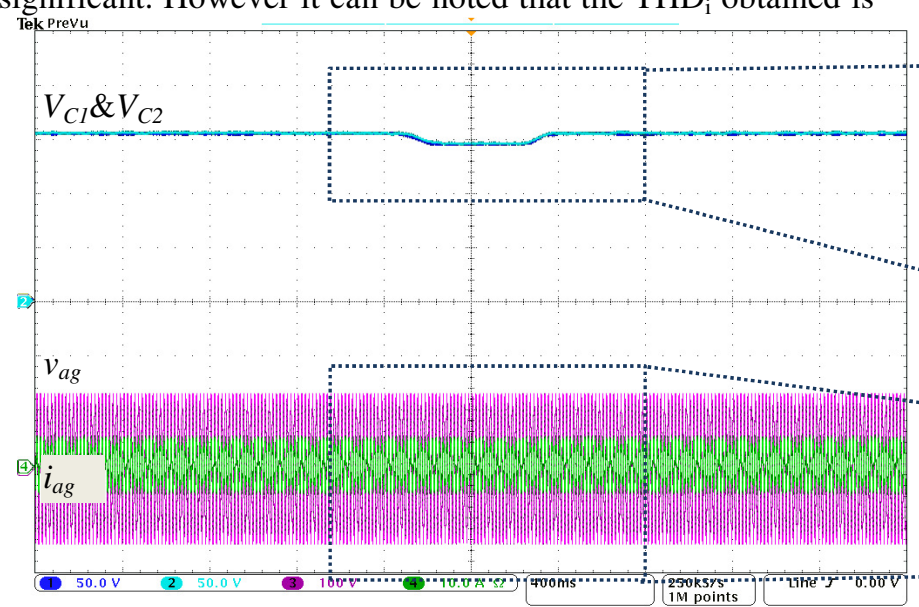

(a) relatively low and an almost unity power factor is attained while the DC voltage ripples are low enough.

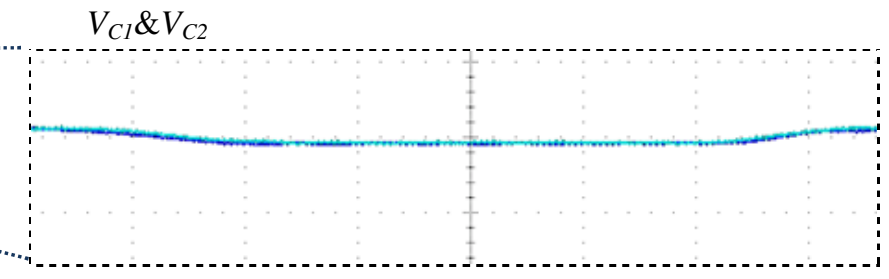

(b)

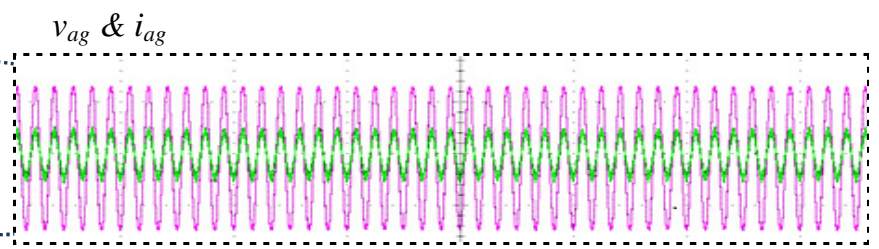

(c)

Fig. 12. Experimental results showing DC voltage variation between $330 \mathrm{~V}$ and $290 \mathrm{~V}$

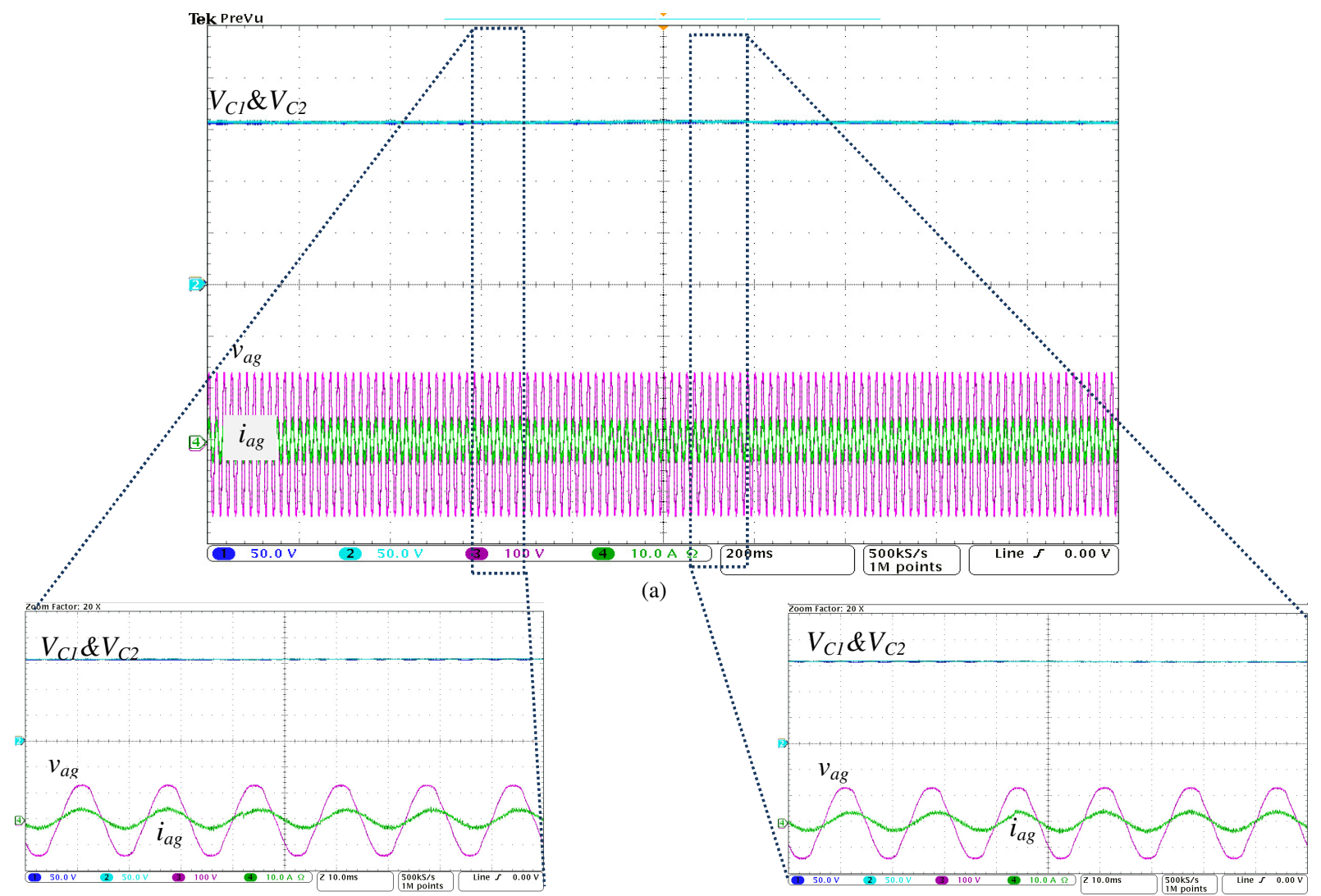

(b)

(c)

Fig. 13. Experimental results during a phase shift in $\mathrm{AC}$ side voltages and currents between $0^{\circ}$ and $30^{\circ}$ 


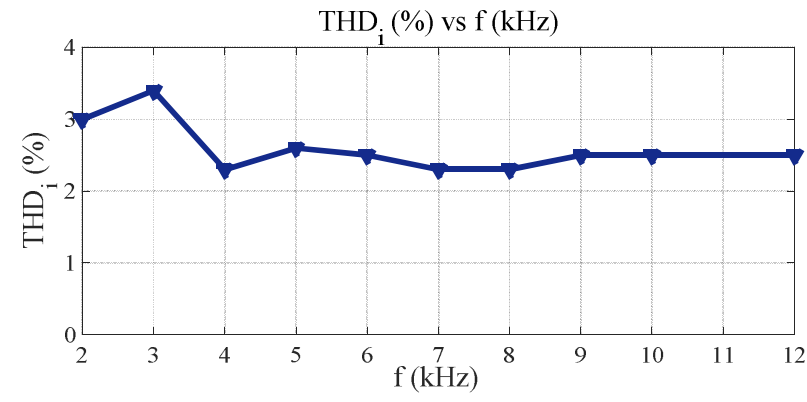

Fig. 14. THDi variation vs switching frequency

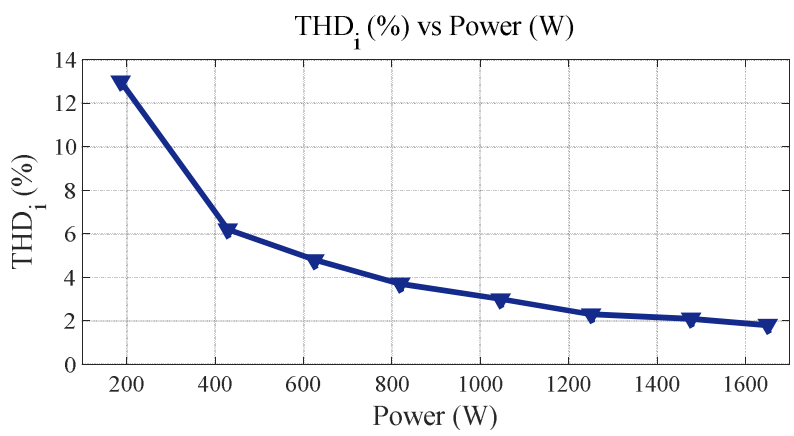

(a)

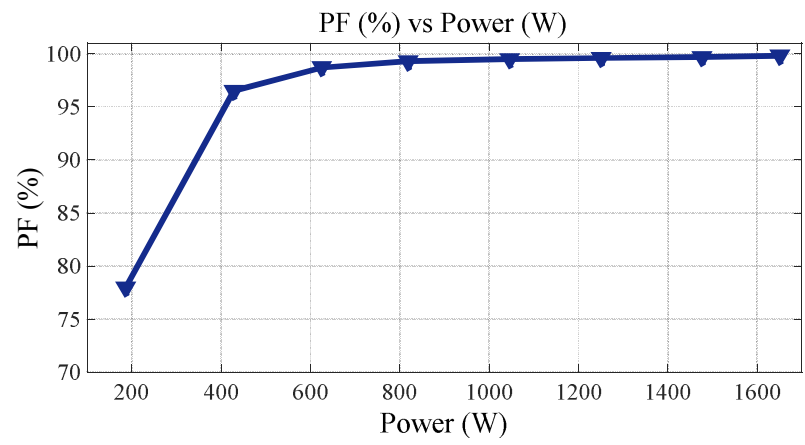

(b)

Fig. 15. Variations of THD and PF as a function of the output power

\section{CONCLUSION}

In this paper a SVM based SMC (called as SMC-SVM) technique has been proposed to control a grid-connected $3 \mathrm{~L}-$ NPC inverter. The SMC part is regulating the current to suppress its harmonics and ensure desired amplitude and phase shift which results in exchanging controlled amount of active/reactive power with the grid. Due to neutral point balancing requirement in DC side of the NPC inverter, SVM switching method with integrated voltage balancing technique is combined with the mentioned SMC. The main advantages of the designed hybrid controller SMC-SVM could be mentioned as decoupled voltage/current control and no need to an external voltage controller for DC capacitors of the NPC inverter. Experimental results show the good dynamic performance and the robustness of the system against external perturbations. The proposed controller is convenient to meet the international codes imposed on grid inverters since it injects a low THD current with low ripples and arbitrary power factor always obtained. The ability of the system to maintain the DC capacitors identically in various conditions

has been acceptably verified. Eventually, it can be concluded that SMC-SVM technique applied on the NPC inverter not only resolves the major drawback of this inverter with DC side voltage balancing but also allows this inverter to be a good candidate in interfacing renewable energy sources to the grid due to several advantages such as lower switching losses, high power factor, low THD grid currents, robustness and operation at constant switching frequency.

\section{REFERENCES}

[18] M. Sharifzadeh, H. Vahedi, R. Portillo, M. Khenar, A. Sheikholeslami, L. G. Franquelo, and K. Al-Haddad, "Hybrid SHM- 
SHE Pulse Amplitude Modulation for High Power Four-Leg Inverter," IEEE Trans. Ind. Electron., vol. PP, no. 99, pp. 1-1, 2016.

[19] H. Vahedi and K. Al-Haddad, "A Novel Multilevel Multi-Output Bidirectional Active Buck PFC Rectifier," IEEE Trans. Ind. Electron., vol. PP, no. 99, pp. 1-1, 2016.

[20] M. Saeedifard, R. Iravani, and J. Pou, "A space vector modulation strategy for a back-to-back five-level HVDC converter system," IEEE Trans. Ind. Electron., vol. 56, no. 2, pp. 452-466, 2009.

[21] B. Wu, Y. Lang, N. Zargari, and S. Kouro, Power conversion and control of wind energy systems: John Wiley \& Sons, 2011.

[22] H. Vahedi, A. Chandra, and K. Al-Haddad, "Five-Level ReducedSwitch-Count Boost PFC Rectifier with Multicarrier PWM," in ECCE 2015-Energy Conversion Congress \& Exposition, Canada, 2015, pp. 2413-2420.

[23] A. Nabae, I. Takahashi, and H. Akagi, "A new neutral-point-clamped PWM inverter," IEEE Trans. Ind. Electron., no. 5, pp. 518-523, 1981.

[24] R. Teodorescu, M. Liserre, and P. Rodriguez, Grid converters for photovoltaic and wind power systems vol. 29: John Wiley \& Sons, 2011.

[25] W. Gao, Y. Wang, and A. Homaifa, "Discrete-time variable structure control systems," IEEE Trans. Ind. Electron., vol. 42, no. 2, pp. 117122, 1995.

[26] A. Lewicki, Z. Krzeminski, and H. Abu-Rub, "Space-Vector Pulsewidth Modulation for Three-Level NPC Converter With the Neutral Point Voltage Control," IEEE Trans. Ind. Electron., vol. 58, no. 11, pp. 5076-5086, 2011.

[27] B. Wu, "Diode Clamped Multilevel Inverters," in High-Power Converters and AC Drives, ed: Wiley-IEEE Press, 2006, pp. 143 177.

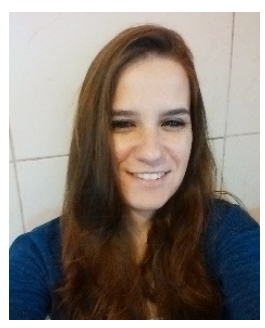

Fadia Sebaaly (S'14) was born in Beirut, Lebanon, in 1986. She received her B.Sc. and M.Sc. degrees both in electrical engineering from the Lebanese University, Faculty of Engineering (II)-Beirut, Lebanon in 2009 and Saint Joseph University, Faculty of EngineeringESIB, Beirut, Lebanon in 2012, respectively.

She is currently pursuing her $\mathrm{PhD}$ at Saint Joseph University, Faculty of Engineering-ESIB, Beirut, Lebanon and Doctoral School of Science and Technology, Lebanese University, Beirut, Lebanon. In summer 2014 \& 2015 she was a trainee in Groupe de Recherche en Électronique de Puissance et Commande Industrielle (GRÉPCI), École de Technologie Superieure (ÉTS), University of Quebec, in Montreal, Canada. Her research interests include power electronics multilevel converters topology, control (predictive and sliding mode controllers) and modulation techniques, power quality, and their applications into renewable energy systems.

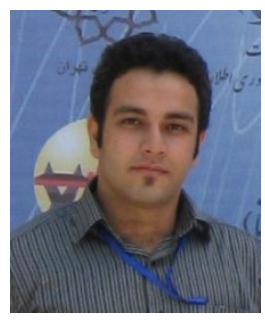

Hani Vahedi (S'10) was born in Sari, IRAN, in 1986. He received his B.Sc. and M.Sc. degrees both in Power electrical engineering from K. N. Toosi University of Technology (KNTU), Tehran, IRAN in 2008 and Babol University of Technology, Babol, IRAN in 2011, respectively.

$\mathrm{He}$ is currently pursuing his $\mathrm{PhD}$ at the École de Technologie Superieure (ÉTS), University of Quebec, in Montreal, Canada, as a member of Groupe de Recherche en Électronique de Puissance et Commande Industrielle (GRÉPCl). His research interests include power electronics multilevel converters topology, control and modulation techniques, power quality, active power filter, and their applications into smart grid, renewable energy conversion, UPS, battery chargers and electric vehicles.

$\mathrm{He}$ is an active member of IEEE Industrial Electronics Society and its Student \& Young Professionals committee.

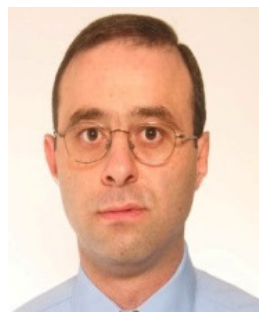

Hadi Y. Kanaan (S'99-M'02-SM'06) received the diploma in electromechanical engineering from Saint-Joseph University of Beirut in 1991, and the Ph.D. degree in electrical engineering from the Ecole de Technologie Supérieure (ETS), Montreal, Canada, in 2002. He is currently a Full-Professor at Saint-Joseph University of Beirut, which he joined in 2001. He is a visiting researcher at ETS since 2004, and associate member of the Canada Research Chair in Energy Conversion and Power Electronics since 2001. His research interests concern modeling and control of switch-mode converters, modern rectifiers, power factor correction, active power filters, and grid-connectivity of renewable energy systems. He is an author of 1 book, 2 book chapters, and more than 170 technical papers published in international journals and conferences. He is an Associate Editor of the IEEE Trans. Industrial Electronics, and member of the IEEE Power Electronics Society (PELS), Industrial Electronics Society (IES) and Industry Applications Society (IAS).

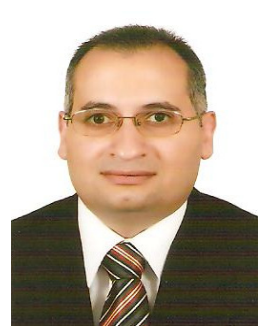

Nazih Moubayed (S'96-M'99-SM'09) got his Diploma of Engineering in Electricity and Electronics (1995) from the Lebanese University (UL), then, in Electrical Engineering, he got his Master (1996) from the Polytechnic National Institute of Toulouse (INPT), his PhD (1999) from the Polytechnic National Institute of Lorraine (INPL) and his and HDR (2011) from UL. Since 1999, he joined the Faculty of Engineering at UL as associate Professor, then, in 2014 he became Professor. He is IEEE Senior Member and associated with other engineering societies. He organized and participates in many conferences. $\mathrm{He}$ is reviewer in different international journals and conferences, and, participated in international research projects. He has authored more than 150 papers published in scientific journals, conferences and books. He had supervised more than 34 Eng., 9 MSc and 5 PhD students. His current researches interests are in the area of power electronics, diagnosis of converter-machine set and energy management power systems.

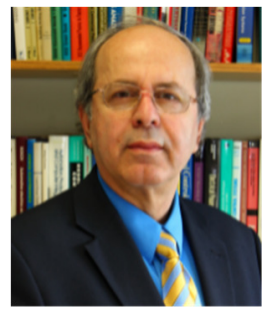

Kamal Al-Haddad (S'82-M'88-SM'92-F'07) received the B.Sc.A. and M.Sc.A. degrees from the University of Québec à Trois-Rivières, Canada, in 1982 and 1984, respectively, and the Ph.D. degree from the Institute National Polythechnique, Toulouse, France, in 1988 all in Power Electrical Engineering. Since June 1990, he has been a Professor with the Electrical Engineering Department, École de Technologie Supérieure (ETS), Montreal, QC, where he has been the holder of the Canada Research Chair in Electric Energy Conversion and Power Electronics since 2002. He has supervised more than 100 Ph.D. and M.Sc.A. students working in the field of power electronics. He is a Consultant and has established very solid link with many Canadian industries. He has coauthored more than 400 transactions and conference papers. His fields of interest are in high efficient static power converters, harmonics and reactive power control using hybrid filters, switch mode and resonant converters including the modeling, control, and development of prototypes for various industrial applications. Prof. Al-Haddad is a fellow member of the Canadian Academy of Engineering. He is IEEE IES President 2016-2017, Associate editor of the Transactions on Industrial Informatics, IES Distinguished Lecturer and recipient of the Dr.-Ing. Eugene Mittelmann Achievement Award. 